\section{Estudo \\ cobebate}

em Cestão

Planejamento
Revista Estudo \& Debate, Lajeado, v. 24, n. 1, 2017. ISSN 1983-036X

DOI: http://dx.doi.org/10.22410/issn.1983-036X.v24ila2017.1060

\title{
O DESPERDÍCIO DE ALIMENTOS: UM ESTUDO DE CASO NA CEASA SERRA-RS
}

\author{
Deivis Cassiano Philereno ${ }^{1}$, Josué Dalegrave ${ }^{2}$
}

\begin{abstract}
Resumo: O objetivo geral é identificar o destino das sobras dos alimentos hortifrutigranjeiros da CEASA Serra, no primeiro semestre de 2015. Para a realização da pesquisa utilizou-se o método exploratório com abordagens qualitativa e quantitativa, por meio de entrevista semiestruturada e questionário estruturado. As entrevistas foram realizadas com o Secretário da Agricultura e com o Gerente da CEASA Serra, já o questionário foi aplicado para 17 comerciantes da CEASA. Na análise qualitativa, observou-se a falta de programas de destinação das sobras dentro da instituição, de investimento do poder público, a desinformação do comerciante e a falta de interlocuçáo entre os envolvidos nesse processo. Por sua vez, na análise quantitativa, constatou-se que 13 dos 17 entrevistados gostariam de doar as suas sobras para um banco de alimentos, pois na concepção dos entrevistados, a própria estrutura da CEASA Serra, não oferece o suporte necessário para que haja menos desperdício de alimentos.
\end{abstract}

Palavras-chave: CEASA Serra. Sobras. Desperdícios.

\section{THE FOOD WASTE: A CASE STUDY IN CEASA SIERRA-RS}

\begin{abstract}
The general objective is to identify the destination of leftover of horticultural foods from CEASA Serra's food crops in the first semester of 2015. The exploratory method used for qualitative and quantitative approaches through a semi-structured interview and a structured questionnaire. The interviews conducted with the Secretary of Agriculture and the Manager of CEASA Serra, and the questionnaire applied to 17 marketers from supply central. In the qualitative analysis, there was a lack of allocation programs for leftovers within the institution, public investment, disinformation of the merchant and lack of interlocution among those involved in this process. On the other hand, in the quantitative analysis, it was verified that 13 of the 17 interviewees would like to donate their leftovers to a food bank, since in the interviewees' conception, the structure of CEASA Serra, itself does not provide the necessary support so that there is less waste of food.
\end{abstract}

Keywords: CEASA Serra. Leftovers. Waste.

1 Faculdade Cenecista de Osório - FACOS.

2 Bacharel em Administração (FSG). Faculdade da Serra Gaúcha (FSG). Supervisor na Randon Implementos. Pós-Graduando em Gestáo Empresarial. 


\section{INTRODUÇÁO}

Segundo dados da Organização das Naçóes Unidas (ONU, 2012), o Brasil é um dos maiores produtores de alimentos do mundo, mas enfrenta dificuldades em relação ao desperdício durante as etapas da cadeia produtiva. Com relação ao total dos desperdícios, estes já são percebidos na colheita do produto, que paira em torno de $10 \%$, prosseguindo nas etapas de transporte e industrializaçáo, somando $50 \%$. Além dessas etapas, as perdas se estendem também para a comercialização $30 \%$ e, ainda, $10 \%$ que são desperdiçados durante o seu preparo (ONU, 2012). Para essa Organização, o Brasil desperdiça aproximadamente $64 \%$ da produção de alimentos gerada anualmente, o que incide diretamente na quantidade e na qualidade dos produtos (ONU, 2012).

Estas e outras informações estão divulgadas em publicaçóes do Ministério da Agricultura Pecuária e Abastecimento (MAPA, 2007). Segundo o próprio Ministério, pesquisa desenvolvida pela Empresa Brasileira de Pesquisa Agropecuária (Embrapa), aponta que no Brasil os desperdícios com hortaliças atingem 37 quilogramas $(\mathrm{kg})$ por pessoa em um ano, sendo que neste mesmo período o Instituto Brasileiro de Geografia e Estatística (IBGE) afirma que são consumidos em média, apenas $35 \mathrm{~kg}$ por pessoa. Estes órgãos apontam que, se os alimentos desperdiçados no Brasil fossem utilizados de maneira consciente poderiam alimentar em torno de 35 milhôes brasileiros (ONU, 2012).

Por sua vez, cabe às Centrais Estaduais de Abastecimentos (CEASA), empresas de capital misto ou ligadas aos estados, promover, desenvolver, dinamizar e organizar a comercialização desses hortifrútis (COMPANHIA NACIONAL DE ABASTECIMENTO, 2009). Ainda na concepção desse mesmo órgão, as centrais são "espaços econômicos e sociais diversificados que reúnem vendedores e compradores, produtores e comerciantes, consumidores e prestadores de serviços, agentes públicos e informais em uma intensa relação comercial e social, realizada em curto espaço de tempo" (CONAB, 2010, p.4)

Diante do fato do desperdício de alimentos hortifrutigranjeiros no Brasil, torna-se relevante identificar como os representantes da central de abastecimento, CEASA Serra, localizada no município de Caxias do Sul, reaproveitam as sobras de alimentos provenientes da comercialização nesse estabelecimento.

Para isso, o referido estudo tem o seguinte problema de pesquisa: quais os destinos das sobras dos alimentos hortifrutigranjeiros da CEASA Serra, no primeiro semestre de 2015? Sendo que a partir desse, tem-se como objetivo geral: identificar o destino das sobras dos alimentos hortifrutigranjeiros da CEASA Serra, no primeiro semestre de 2015. Para isso, os objetivos específicos são: a) identificar se a CEASA Serra, possui algum programa de conscientização dos comerciantes e se há o reaproveitamento das sobras dos alimentos hortifrutigranjeiros gerados no seu estabelecimento; b) identificar se existem ações públicas municipais para o reaproveitamento dos alimentos hortifrutigranjeiros da CEASA Serra; e c) identificar a percepção dos comerciantes da CEASA Serra sobre a existência de programas de destinação das sobras dos alimentos hortifrutigranjeiros.

A importância desse estudo se dá pelo reaproveitamento dos alimentos e a forma como esta é discutida pela gestão pública, pelos gestores da CEASA Serra, e percebida pelos próprios comerciantes, uma vez que o assunto em pauta está relacionado diretamente com 
a redução dos resíduos orgânicos e o beneficiamento da família de baixa renda (SILVA; RAMOS, 2009). Ainda, sobre este olhar, o aproveitamento dos alimentos hortifrutigranjeiros como forma de estimular o consumo desse grupo de alimentos, é uma prática alimentar saudável e contribui para a promoção da saúde (MINISTÉRIO DA SAÚDE, 2004).

\section{A PRODUÇÁO DE ALIMENTOS E O DESPERDÍCIOS}

A produção de alimentos é equivalente a 3,9 bilhóes de toneladas sendo que um terço é desperdiçado, levando em consideração a saída do produto do campo ao consumidor (ONU, 2012; BUENO, 2013). Além disso, na concepção da ONU (2012) e de Bueno (2013), se percebe o quanto é ineficiente os processos de controle e reutilização praticados no mundo.

Para evitar a escassez de recursos que amedronta o mundo, economistas estudam processos produtivos que levem a minimizar os desperdícios, utilizando as potencialidades a pleno, e agilizando as formas de produção e distribuição dos recursos (SANDRONI, 2001).

Segundo a ONU (2012), há previsão de que a população mundial alcançará 9 bilhões de pessoas até 2050 e que para poder atender essa demanda será necessário um crescimento de produção de alimentos por volta de $70 \%$, parte disso poderia ser suprida com açóes de combate ao desperdício. Inclusive, a ONU (2012) afirma que há diferentes formas de desperdícios entre os países desenvolvidos e subdesenvolvidos. Ou seja, enquanto nos países mais ricos os desperdícios na sua grande maioria ocorrem no consumidor final, nos países em desenvolvimento a maior incidência de perda acontece na produção e transporte dos alimentos. Para Bueno (2013), perde-se muito do campo aos portos, o que poderia ser evitado com simples açóes de infraestrutura.

Conforme a análise de Carvalho (2009), o Brasil está entre os 10 países que mais desperdiçam alimentos no mundo, sendo que as fatores causadores deste estáo na má qualificação e preparação de pessoas que realizam as colheitas, falta de conhecimento técnico do produtor, transportes inadequados, más condições de armazenamento, centrais de abastecimento despreparadas e desperdícios domésticos.

Além disso, outros fatores relacionados no processo de desperdício também devem ser elencados, tais como água, degradação do solo, mau aproveitamento da mão de obra, desgaste do maquinário e equipamentos, adubo e matéria-prima (SANDRONI, 2001).

\section{Retrato da fome no mundo e no Brasil}

A fome global é um aspecto a ser trabalhado, considerando que uma em cada oito pessoas passam fome no mundo ONU (2012). Esse dado só não é maior porque nas últimas duas décadas reduziu-se a quantidade de pessoas com alimentação abaixo das necessidades mínimas (de $18,6 \%$ para $12,5 \%$ da população mundial). No entanto, esses números são elevados quando considerando os avanços da tecnologia na agricultura, a alta produtividade das colheitas e o desperdício de alimento gerado no mundo (ONU, 2012).

A Secretaria de Assuntos Estratégicos (SAE, 2013) divulgou o mapa da fome no mundo, elencando as principais regióes globais onde a fome tem destaque. Considerando os 
números em milhões de pessoas, na primeira posição se encontra a Ásia Meridional (295), seguida da África Subsaariana (223), Ásia Oriental (167), Sudeste Asiático (65), América Latina e Caribe (47), Ásia Ocidental e África do Norte (24), Países Desenvolvidos (16), Ásia Central (6), Oceania (1). O BRIC (grupo de países formado por Brasil, Rússia, Índia e China) é responsável por quase metade das pessoas em condiçôes de alimentação abaixo da linha nutricional adequada, sendo que no Brasil, 13 milhóes de pessoas se encontram nesta situação, na Rússia, 7 milhões, na Îndia 213,8 milhões e na China 158 milhões de pessoas (SAE, 2013).

Nesse contexto, Carabajal (2010) expóe que em 2008 no sul da Ásia, havia 430 milhóes de pessoas em estado de fome extrema e 313 milhōes nas mesmas condiçóes na África. Ainda no mundo, entre 815 milhōes e 1,1 bilhão de pessoas não conseguem ter alimentação adequada e vivem com menos de um dólar americano (U\$ 1.00) diário, sendo que dessa populaçấo, por volta de 24 e 25 mil pessoas morrem de fome diariamente.

Segundo a Comissão Econômica para a América Latina (CEPAL, 2004), foram realizadas Reunióes de cúpula em Roma com o objetivo de debater os meios e progressos a serem realizados para combater a fome. Com isso, em 2001, na segunda reuniáo de cúpula foram verificadas as necessidades de desenvolver decisōes políticas e recursos financeiros que se traduzissem em redução da fome no mundo. Uma vez que em 2001, os números indicavam que a média de declínio de pessoas com fome era de 6 milhōes/ano, porém havia sido estipulada, na primeira reunião de cúpula, uma expectativa de redução de 22 milhóes/ ano (FAO, 2001).

$\mathrm{Na}$ África, o principal aspecto causador do alto índice de fome é a instabilidade econômica que a região sofre, bem como a falta de desenvolvimento dos países, aspectos naturais desfavoráveis e a má administração pública (ALB, 2009). Algumas destas características retratam o cenário existente no Brasil, que possui proporçóes continentais.

Já o Brasil, produz cerca de 140 milhôes toneladas de alimentos todos os anos, estando entre os maiores exportadores de produtos agrícolas do mundo, mas, em contraponto, milhóes de pessoas não possuem acesso a alimentos em quantidade e qualidade suficientes, muitas vezes o desconhecimento sobre a utilização dos alimentos induz ao mau aproveitamento, o que proporciona o desperdício de toneladas de recursos alimentares (GONDIM et al., 2005).

Os maiores problemas do Brasil são a fome e o desperdício de alimentos, o que é um contraste para um país que é um dos maiores produtores e exportadores de alimentos, e mesmo assim, está entre os que mais desperdiçam (TORRES et al., 2000).

Para a ONU (2012), no Brasil, o percentual de subnutridos e pessoas que passam fome diminuiu de $14,9 \%$ de 1990 a 1992 para 6,9\% de 2010 a 2012, queda esta, impulsionada pelos projetos sociais incentivados pelo governo brasileiro, ainda assim, por volta de 13 milhōes de pessoas passam fome ou estão em estado de desnutrição.

De acordo com o IBGE (2010) na área urbana 11,4\% em 2004 e 6\% em 2009 dos domicílios passavam por situaçóes de fome em algum momento, já no meio rural esses índices eram de $17,0 \%$ e 9,0\%, sendo que em $2004,11,5 \%$ da populaçáo negra ou parda o 
Brasil vivia na situação de falta de alimentos, em comparação com a população branca em que o percentual era de $4,1 \%$.

As regióes Norte e Nordeste são as mais afetadas pela fome. Os índices são 3,1 vezes maior em 2004 e 3,5 vezes maior em 2009 do que nos domicílios situados no Sul, sendo que dos 14 milhóes de pessoas que passam fome, $52 \%$ residem no Nordeste (IBGE, 2010). Os estados do Nordeste onde a fome tem seus maiores percentuais são o Maranhão e o Piauí (IBGE, 2010). Em contrapartida o estado de Santa Catarina, Rio Grande do Sul e Paraná, são os que garantem o melhor acesso a uma alimentação de maneira adequada e em quantidade suficiente para seus moradores.

\section{Conceito e fatores causadores do desperdício na cadeia produtiva}

Para Sandroni (2001), o desperdício se resume ao ato ou efeito de desperdiçar, gastar inutilmente ou perder determinado bem. Entende-se por perdas, a parte física da produção que não é destinada ao consumo, pelo motivo de depreciação da qualidade dos produtos, deterioração, causada por amassamentos, cortes, podridóes e outros fatores. Os alimentos são desperdiçados, quando, em boas condições fisiológicas, e são desviados do consumo para o lixo, esta situação pode ser ilustrada, pelas sobras das refeições nos pratos em residências e restaurantes, aproveitamento parcial de frutos, raízes e folhas não utilizadas, pelo descarte dos produtos in natura com boas condiçóes físicas, em razão de vencimento do prazo de validade estipulado e, até mesmo pela falta de alternativas de aproveitamento (LANA et al., 1999).

Rebesco (2004) alerta que as más condiçōes do transporte, manuseio excessivo, embalagens ásperas, condiçóes de armazenamento inadequadas e o clima brasileiro são os principais fatores de desperdício de alimentos no país. Complementa ainda, o autor, que o Brasil, não possui a cultura de investir na área logística deste negócio e por este motivo muitas vezes prejudica uma produção de qualidade vinda do campo, o que interfere diretamente na maneira e condiçóes que o produto chega às centrais de abastecimento.

$\mathrm{Na}$ safra de 2001, foram colhidas 15 milhóes de toneladas de produtos hortícolas, desses foram desperdiçadas mais de cinco milhóes de toneladas, o que se pode dizer que a quantidade perdida seria suficiente para abastecer $29,3 \%$ da população brasileira, sendo assim, entende-se que por volta de 53 milhóes de habitantes poderiam usufruir destes recursos que são gerados em grande parte pelas centrais de abastecimento (VILELA et al., 2003). Chitarra e Chitarra (1990) sinalizam as principais causas de desperdício e os meios de controles possíveis para minimizá-las conforme Quadro 1. 
Quadro 1:Principais causas e meios de controle de perdas em frutos e hortaliças

\begin{tabular}{|l|l|}
\hline \multicolumn{1}{|c|}{ Causas de Perdas } & \multicolumn{1}{c|}{ Meios de Prevençáo } \\
\hline Esmagamento & Colheita e manuseio cuidadosos, embalagem protetora. \\
\hline Apodrecimento & Manter a casca intacta, boa sanidade, armazenamento a frio. \\
\hline Senescência & $\begin{array}{l}\text { Armazenamento a frio, comercialização imediata, processamento em } \\
\text { produto estável. }\end{array}$ \\
\hline Produtos murchos & Manter em ambiente com elevada umidade relativa. \\
\hline
\end{tabular}

Fonte: Chitarra e Chitarra (1990)

Estudos apontam que $80 \%$ dos desperdícios são resultantes de manuseio, transporte, clima, más condiçóes de armazenamentos e falta de conhecimento técnico (EMBRAPA, 2014). Desta maneira as perdas são resultantes de processos do pós-colheita que quando mal executados propiciam causas que se traduzem em desperdícios nas centrais de abastecimento, essas perdas são devidas ao nível de maturidade e condiçóes de armazenamento e estocagem dos produtos, propiciando a geração de sobras nos estabelecimentos (CHITARRA; CHITARRA, 1990).

As embalagens para Moura e Banzato (1997), são um fator primordial dentro de suas atribuiçóes de envolver, conter e proteger produtos durante o transporte, armazenamento e comercialização. Já Bordin (2000) cita que as embalagens de frutas e hortaliças são as etapas de maior criticidade e importância na logística entre o produtor e o cliente final.

$\mathrm{O}$ uso adequado das embalagens é importante para garantir a qualidade do produto, de acordo com Cerqueira-Pereira (2009), muitas vezes se tem a ideia que o custo de embalagens apropriadas torna o custo final do produto mais elevado, porém este fator pode provocar justamente o inverso, pois eliminaria muitos dos desperdícios desnecessários decorrentes de embalagens inapropriadas e, na maioria das vezes, os produtos são acondicionados em caixas confeccionadas em madeira, papeláo ou plásticos. A Instrução Normativa $\mathrm{N}^{\circ}$ 9, de 12/11/02, da Secretaria de Defesa Agropecuária do Ministério da Agricultura, Pecuária e Abastecimento (SDA/MAPA), estabelece que as embalagens devam ser descartáveis ou retornáveis e ainda se retornáveis, devem ser higienizadas a cada uso (REBESCO, 2004). Além de ser uma ação de higiene para o transporte, as embalagens de madeira podem causar danos aos alimentos por terem cantos vivos e também por proliferar bactérias que causam o apodrecimento e a desvalorização comercial (REBESCO, 2004).

De acordo com Vilela et al. (2003) muitas vezes os produtos são "forçados" a entrar nas caixas, esse procedimento é justificado pelos produtores como forma de impedir que os produtos fiquem soltos dentro da embalagem, minimizando os efeitos do atrito com a caixa durante o transporte, o que acaba gerando perda de boa parte dos produtos, que em alguns casos podem chegar a $40 \%$.

Com relação a isso, um trabalho de orientação vem sendo desenvolvido junto aos agricultores e recebedores/distribuidores das mercadorias para o processo de embalagem adequado dos produtos, o que proporciona que atualmente $86 \%$ dos produtos 
comercializados nas Centrais de Abastecimento Brasileiras já estejam acondicionados em embalagens que atendem às exigências da lei (IBGE, 2004).

Mesmo com a sua modernização, existe a predominância de transportes inadequados como em caminhóes cobertos com lonas, sem refrigeraçáo e sem controle de temperatura, propiciando um cenário facilitador do desperdício e da perda da qualidade dos produtos (LUENGO et al., 2007).

Para Cerqueira-Pereira (2009) o transporte inapropriado é proveniente da falta de uma legislação que normatize o transporte de produtos perecíveis no Brasil, sendo que normalmente os produtos são transportados por meios que não possuem o mínimo de acondicionamentos necessários e específicos para o transporte desses tipos de produtos. Junqueira (1999) menciona que o transporte é a principal etapa deste fluxo e a falta de um plano de ação logístico eficaz, aliado às situaçóes precárias das estradas, faz com que $20 \%$ da safra colhida seja desperdiçada no caminho entre campo e o consumidor.

Ainda dentro desse contexto, o grande responsável pelo desperdício no transporte é o modal rodoviário que equivale a $60 \%$ de todo escoamento e movimentação da produção do país, o que demonstra a necessidade de uma infraestrutura de estradas adequadas para a distribuição de hortifrutigranjeiros no território nacional (GEIPOT, 2001).

Pesquisas realizadas pela Confederação Nacional dos Transportes (CNT, 2005a), apontam que o estado de conservação das rodovias brasileiras se apresentam em estado crítico, uma vez que $72 \%$ delas mostram alguma dificuldade ou ponto negativo, sendo definidas como "Deficiente", "Ruim" ou "Péssimo". Já considerando apenas as rodovias pavimentadas, a mesma fonte informa que os números melhoram um pouco passando para $54,6 \%$ da totalidade.

No Brasil, cerca de 150 mil quilômetros das estradas são asfaltadas, enquanto por volta de 1,5 milhão são de chão batido, no qual o grande problema se torna a baixa conservação das rodovias, aumentando o custo de transporte e o tempo de entrega, refletindo em um gargalo para a logística nacional (SILVA; BAZOLI, 2010).

\section{Centrais de Abastecimento Brasileiras e o desperdício}

No país, atualmente existem estruturas para abastecimento de hortifrútis e produtos agrícolas denominadas Centrais Estaduais de Abastecimento (CEASA), sendo que nessas estruturas são geradas grandes quantidades de resíduos, que se adequadamente aproveitados poderiam alimentar ou servir de insumo para outros produtos (CAMPANI, 2003).

As centrais de abastecimento brasileiras em 2007 comercializaram em torno de 15,48 milhóes de toneladas em todo país (CONAB, 2009). Segundo a Embrapa (2014), 30\% do que é produzido é desperdiçado durante a comercialização, sabendo desta informação mensura-se que parte deste montante é de responsabilidade das centrais, sendo assim, aproximadamente cinco milhóes de toneladas são desperdiçadas todo ano nas centrais do país.

Contudo, ressalta Campani (2003) que os resíduos produzidos pelas centrais de abastecimento são na sua maioria de material orgânico e podem ser divididos em quatro 
tipos, primeiro os que não estão em condições de comercialização, mas podem ser consumidos; segundo os que estão em estado de maturação um pouco avançados, mas podem ser transformados em doces e conservas ainda para o consumo humano; terceiro os que estão em estágio avançado de maturação, mas que podem servir para compor e balancear raçóes animais; e por fim o quarto, que são os que não servem para alimentação animal, mas servem para compostagem.

Uma das maneiras encontradas pelas centrais de abastecimento para combater o desperdício foi o aproveitamento integral de frutas e hortaliças, utilizando todos os recursos possíveis do alimento na transformação em novos produtos, mantendo o valor nutricional e reduzindo o desperdício e produção de lixo de forma eficaz (SANTANA; OLIVEIRA, 2005).

O projeto Banco de Alimentos é o principal meio utilizado pelas centrais no combate ao desperdício, sendo o mais utilizado e incentivado pelo Ministério do Desenvolvimento Social (MDS), no qual consiste na doação dos alimentos sem valor comercial para o produtor ou comerciante, sendo armazenado e distribuído gratuitamente, às entidades cadastradas (ABRACEN, 2011).

$\mathrm{Na}$ CEASA/RS (2014), reaproveitar os alimentos para consumo humano não é apenas uma opção, mas um dos seus objetivos. Além disso, reaproveitar os resíduos em forma de fertilizantes e ou produção de gás, poderá suprir em até 30\% a energia também está nos planos da Central. Na concepção da própria instituição, esse projeto deve estar em funcionamento no máximo em dois anos.

Muitos programas elaborados e administrados pelas Centrais de Abastecimento brasileiras são relacionados a programas de inclusão e representação social típicos das cidades. Esses programas, são razoavelmente difundidos por meio de uma variedade de projetos que incluem bancos de alimentos, programas de distribuição, fábricas de concentrado alimentar, programas de educação alimentar e nutricional, que beneficiam uma grande quantidade de instituiçóes assistenciais e diminuem a concentração das populaçóes em volta dos entrepostos (CUNHA, 2006).

Os programas desenvolvidos nas Centrais de Abastecimento voltados à segurança alimentar têm expressiva relevância em termos de ganhos social, embora haja dificuldades das Centrais em desenvolver uma metodologia consistente de operacionalização e articulação social, ou até mesmo quanto ao relacionamento com as gestôes administrativas governamentais, possibilitando o envolvimento e participação social na gestão e distribuição desses benefícios (CUNHA, 2006).

\section{PROCEDIMENTOS METODOLÓGICOS}

Nesse estudo foi aplicado o método qualitativo e posteriormente quantitativo, pois segundo Miguel (2010) no método qualitativo a preocupação é obter informações sobre a perspectiva dos indivíduos, bem como interpretar o ambiente em que a problemática acontece o que implica no ambiente natural dos indivíduos e no ambiente da pesquisa. Richardson (1999) analisa que métodos de abordagem qualitativa permitem ao pesquisador compreender detalhes do comportamento dos indivíduos e facilitam processos de mudanças. 
Já o método quantitativo para Richardson (1999) são procedimentos sistemáticos que descrevem e desvendam elementos com margem de segurança e exatidáo dos resultados, como nos métodos estatísticos. A utilização de diferentes métodos, qualitativos e quantitativos, dão mais credibilidade às conclusôes, do que a utilização de apenas uma (MAZZARINO et al., 2016).

Para a realização deste estudo foi necessária uma abordagem exploratória uma vez que trata de um assunto pouco debatido, contextualizado e com poucas informaçóes disponíveis (HAIR, et al., 2005). Sendo assim, o estudo buscou verificar condições específicas da central de abastecimento CEASA Serra, caracterizando a utilizaçáo do método de estudo de caso, esta técnica é utilizada quando a pesquisa é restrita a determinado número de experiências ou local, geralmente envolvem profundidade e detalhamento do objeto estudado (VERGARA, 2005).

Ainda foram coletados dados por meio de análise documental e de observação do ambiente, buscando contrapor as informaçóes retiradas dos diferentes tipos de coletas de dados aplicados na pesquisa. Para Gil (2012) a observação é fundamental para o desenvolvimento da pesquisa, pois serve de base para uma investigação detalhada juntamente com outros métodos ou até mesmo exclusivamente.

A amostra da pesquisa realizada foi composta por três grupos, sendo a primeira composta pelo representante da gestão pública de Caxias do Sul, realizada com o secretário da agricultura, a segunda pelo gestor da CEASA Serra e a terceira, com 17 dos 26 comerciantes que atuam na central de abastecimento. Porém, cabe salientar que existem 32 boxes, na CEASA Serra, mas seis comerciantes possuem dois boxes cada, o que gerou uma amostra de 26 entrevistados. As amostras foram escolhidas levando em conta a melhor forma de solucionar o problema de pesquisa, facilitando o trabalho do pesquisador.

Nas três amostras foram utilizadas a pesquisa não probabilística por conveniência, no qual o pesquisador atua buscando realizar a pesquisa com amostra e população de mais fácil acesso, a fim de agilizar e reduzir custos da pesquisa,- uma vez que esta demanda tempo e dinheiro do pesquisador. Porém, na terceira etapa, buscou-se a totalidade dos comerciantes da CEASA Serra, o que se caracteriza como um Censo, o que para Bueno (2007), se trata de um alistamento geral de uma população.

Os dados qualitativos foram coletados com base em entrevista gravada, com um roteiro de questōes abertas e semiestruturada para o integrante da gestão pública e da Gestão da CEASA Serra, no qual os autores Philereno et al. (2015), comentam que as entrevistas gravadas geram uma maior fidelidade na hora da transcrição das falas. Por sua vez, o roteiro de entrevista foi adaptado da dissertaçáo de Oliveira (2012), com isso a pesquisa teve o intuito de obter uma maior amplitude das respostas adquiridas já que se tratou de uma abordagem qualitativa. Para Roesch (2006) a entrevista é fundamental para compreender o ponto de vista do entrevistado com relação ao estudo pesquisado podendo influenciá-lo para a resolução das questóes estudadas.

Desta maneira foi entrevistado o integrante da primeira amostra no dia 27 de Abril de 2015, na Secretária da Agricultura. A entrevista foi agendada por meio de telefonema, após aceitação do entrevistado, enviou-se e-mail para confirmaçáo da data, hora e local da 
entrevista. A mesma abordagem de agendamento foi utilizada para a formação da segunda amostra, no qual se entrevistou o gerente da central de abastecimento no dia 25 de abril de 2015 na própria instituição.

Já, para a coleta de dados quantitativos junto aos comerciantes da CEASA Serra foi utilizado um questionário estruturado com questóes abertas e fechadas além da utilização da escala Likert, que para Gil (2012) possibilita a manifestação de opinióes ou atitudes em caráter ordinal sem medir o quanto é favorável ou não uma atitude.

O questionário teve como base para adaptação um questionário de Castellanelli (2008), buscando extrair a visão do comerciante com relação ao assunto de pesquisa. Segundo Roesch (2006) o questionário é um conjunto de questōes que exigem planejamento anterior com base no problema de pesquisa visando responder e desenvolver soluçóes adequadas por meio das questóes aplicadas. Para isso os questionários foram distribuídos presencialmente na CEASA Serra no dia 25 de abril de 2017 para todos os comerciantes responsáveis pelos boxes da central.

No dia 15 e 16 de abril efetuaram-se os pré-testes averiguando se as respostas correspondiam com a busca da resolução do problema de pesquisa, neste dia foi realizado o pré-teste com um ex-vereador do município para avaliar o roteiro de perguntas voltadas para a gestão pública, já para o roteiro a ser aplicado aos gestores da CEASA realizou-se o pré-teste com o ex-coordenador da empresa na mesma data. No segundo dia solicitou-se a três feirantes que comercializam seus produtos na Rua Bento Gonçalves, Caxias do Sul, que respondessem ao questionário voltado aos comerciantes da CEASA. Gil (2012) avalia o pré-teste como um meio que o pesquisador tem de avaliar a precisão e qualidade dos questionamentos através de testes prévios, buscando certificar a qualidade na elaboração do questionário. Tanto para a aplicação das entrevistas como para os questionários foi realizada uma validação com o professor orientador e outro professor especialista da área no dia 22 de abril de 2015.

Com relação à aplicação dos questionários, tanto qualitativo quanto quantitativo, explicou-se aos respondentes o seu objetivo, deixando-os a vontade para participar ou náo da entrevista, não gerando desta forma, qualquer constrangimento. Este fato se comprova pelo número de questionários entregues, 26, aos comerciantes e os 17 recebidos. A pesquisa também não tem nenhum vínculo com projetos de pesquisas e da mesma forma, não apresenta nenhuma relação com a Instituiçáo de Ensino Superior (IES), este trabalho foi realizado como meio da obtenção do título de Bacharel em Administração.

Para a análise de dados considerando a abordagem qualitativa foi utilizado análise de conteúdo no qual no entendimento de Roesch (2006) tem a finalidade de propiciar ao entrevistador um questionário que possibilite a fácil compreensão do ponto de vista, perspectiva e entendimento do entrevistado. Para Gil (2012) a análise de conteúdo tem como objetivo tornar os dados coerentes de modo a validar a perspectiva do entrevistador com relação às respostas do entrevistado.

$\mathrm{Na}$ abordagem quantitativa foi realizado por meio de estatística descritiva com o auxílio do programa Excel, possibilitando a elaboração de gráficos e demonstrações de percentuais, médias, entre outros. 


\section{ANÁLISE DOS DADOS}

Primeiramente, foi realizada a entrevista com o Secretário da Agricultura do município de Caxias do Sul-RS, posteriormente com o Gestor da CEASA Serra e por fim com os comerciantes.

Ao questionar o Secretário sobre o destino das sobras proveniente da CEASA Serra, este mencionou a falta de uma atuação mais eficiente por parte dos órgãos públicos. A informação relatada pelo secretário vai de encontro ao pensamento de Mauss e Souza (2008), que afirma que a gestão pública deve prestar o serviço público com maior grau de qualidade possível com os recursos disponíveis.

Segundo ainda informaçóes do secretário, a central de abastecimento de Caxias do Sul apresenta características diferentes das demais centrais do país, pois ela é administrada por um consórcio representado por 11 municípios. Este consórcio se formou em 1998, pois decidiram fechá-la a estes municípios em conjunto, resolvendo assumir a sua gestão e mantê-la aberta para o bem dos comerciantes, produtores e população. A CEASA Serra é uma das poucas centrais que não se encontra com déficit e náo conta com dinheiro público no seu dia a dia, os investimentos normalmente são feitos a partir de capital próprio e eventualmente com recursos estaduais e federais. Assim, dificultando a elaboração de açóes que melhorem as condiçóes de destinação das sobras e redução dos desperdícios. Dessa forma, segundo o Secretário, se torna inviável para o município de Caxias do Sul, arcar com todos os investimentos de forma individual, e se fosse para fazer os respectivos investimentos, deveriam ser realizados por todos os municípios participantes do consórcio.

Ainda quanto ao desperdício, uma prática adotada pela Gestão Pública no município de Caxias do Sul junto aos produtores foi a criação das feiras ponta de safra, alocada em três pontos estratégicos do município, cujo objetivo é o de comercializar a custo mais acessível os produtos hortifrutigranjeiros que não foram comercializados dentro da CEASA Serra e provavelmente seriam jogados fora por falta de pessoas, para manipular e utilizar estes alimentos. Esta ação desenvolvida pelo município de Caxias do Sul contribui para a redução do desperdício dos alimentos oriundos da CEASA Serra.

Outro meio de utilização dos produtos que não seriam aproveitados na CEASA Serra e que a Gestão Pública indica como meio de destinar o que seriam sobras na central, é um programa relacionado à coleta seletiva no município de Caxias do Sul, no qual busca trocar reciclados por hortifrutigranjeiros numa escala $4 \mathrm{x} 1$, que a cada quatro q de material reciclado são trocados por um (1) $\mathrm{kg}$ de produtos de época, com intuito de sanar as necessidades nutricionais da população de baixa renda.

Para o secretário da agricultura faltam condições de processamento para os produtos da CEASA Serra, o que possibilitaria assim que o período de comercialização fosse maior, reduzindo o desperdício, que na concepção dele, apesar da sua importância, torna-se pouco expressivo quando comparado à farta produção da região.

Para o secretário a falta de conscientização é o principal fator gerador do desperdício dentro da CEASA, uma vez que, ainda, se usam algumas caixas de madeira, o que não propicia uma movimentação adequada dos produtos. Segundo Cerqueira-Pereira (2009) o uso adequado das embalagens é fundamental para garantir a qualidade dos produtos até o 
momento da comercialização, já para Bordin (2000) a embalagem se trata do ponto mais crítico nos processos logísticos de frutas e hortaliças.

Nestas circunstâncias com o intuito de aprofundar o conhecimento de como é destinada as sobras de alimentos da CEASA Serra, se propôs a entrevista com o gerente da instituição, este esclareceu que o produtor traz para a central de abastecimento produtos que estáo ainda em fase de maturaçáo e que, portanto, possuem um tempo maior para sua comercialização, e também que o produtor realiza uma triagem no qual separa em sua propriedade os produtos que pode comercializar, retirando os produtos que teoricamente seriam jogados fora e destinam as indústrias de processamento de alimentos, tanto para trato animal, como para produçáo de geleias ou adubo dependendo do grau de maturaçáo ou dano. Práticas essas que estão alinhadas à visão de Campani (2003), que orienta quanto à divisão das sobras com relação a sua destinação adequada e reaproveitamento.

Com base na afirmação do Gerente, pode-se verificar a contradição quanto à disponibilizaçáo do produto por um período maior, uma vez que o secretário da agricultura menciona a falta de processamento dos produtos. A princípio, os únicos meios de aproveitamento das sobras da CEASA Serra são o banco de alimentos e o recanto solidário no qual o produtor pode doar os produtos que não conseguiu comercializar. De acordo com a ABRACEM (2011), essas instituiçóes apresentam as melhores condiçôes em termos estruturais para que este alimento alcance as classes menos favorecidas.

Também constatou-se na entrevista, que muitos produtos não comercializados nesta instituição, são simplesmente jogados no chão e misturados com o lixo seletivo e acabam tendo como destino final o aterro sanitário. Cabe ainda ressaltar que este material poderia ser reutilizado/trabalhado em forma de adubo orgânico, ao invés de ser meramente descartado em aterros sanitário. Campani (2003) menciona que todo o material orgânico provenientes das centrais de abastecimento pode ser aproveitado ou reutilizado de diferentes formas, de acordo com seu grau de maturação.

Segundo a gestão da CEASA Serra, a entidade já identificou a má reutilização destes produtos e está elaborando um projeto que possa aproveitar as sobras na forma de adubo orgânico. Para isso, a central de abastecimento tem como objetivo enviar estes resíduos às indústrias de transformações, para que possam transformá-los em adubo e desafogar o aterro sanitário. Campani (2003) aborda em sua teoria as quatro fases de destinação do alimento oriundo das centrais de abastecimento na qual uma delas trata em específico sobre a transformação das sobras em adubo orgânico. Outro ponto salientado pelo gestor da referida entidade está na elaboração de um programa de conscientização dos comerciantes, a fim de propiciar instruçôes adequadas de combate ao desperdício e na destinação correta das sobras.

O gestor ainda salientou sobre a possibilidade de utilizar o produto que não está podre na forma de geleias, para isso, esses produtos seriam destinados a uma cooperativa de transformação. Campani (2003) alerta sobre a possibilidade de utilização do alimento que está com certo grau de maturação e não seria comercializado nas centrais de abastecimento. Para o referido entrevistado, este projeto teria como principal objetivo, buscar a reduçáo, a reutilização e a reciclagem (3R) das sobras. Silva (2003) e Ruffino (2001) salientam a 
importância do princípio do 3R, isto é, da redução da fonte geradora, reutilização direta dos produtos e reciclagem dos materiais.

Já com relação à aplicação dos questionários com os comerciantes, pode-se observar que seis dos 17 comerciantes relataram algum tipo de insatisfação com relação aos programas que deveriam conscientizar sobre o assunto desperdício e destinação das sobras. Estes comerciantes alegaram sobre a falta de práticas mais eficientes de propagação das informações.

Constatou-se que na concepçáo dos comerciantes, que parte dos produtos comercializados na CEASA Serra, são provenientes da Serra Gaúcha, e outros oriundos de São Paulo, Minas Gerais, Bahia, Pará, Maranhão, Espírito Santo, Rio Grande do Norte, Goiás, Paraná e uma participação menor de outras regiôes do estado.

Os comerciantes da central de abastecimento trabalham em sua maioria com a comercialização por caixas, facilitando o processo de entrega e minimizando o desperdício por baldeação de embalagens e transporte inadequado, mesmo assim, relatam o desperdício médio de duas caixas de hortifrutigranjeiros por boxe. Apesar do desperdício de duas caixas, os comerciantes ainda consideram como pouco expressivo a quantidade de alimentos que acaba sendo jogado fora.

Ao mesmo tempo, foram observados que 11 comerciantes se disponibilizariam a participar de programas de reaproveitamento a ser divulgado pela CEASA Serra ou pela prefeitura, sendo que 13 deles teriam como intuito, ajudar pessoas carentes ou de participação em programas de caráter social. Já 13 entrevistados, preferem doar suas sobras para o banco de alimentos, pois este se encontra localizado na própria entidade. Os demais relataram não terem interesse em participar deste tipo de programa.

Quando abordadas as principais causas que propiciam a geração dos fatores do desperdício, os comerciantes indicaram a própria estrutura da central de abastecimento. Dos pesquisados, nove se declaram insatisfeitos de alguma forma com a estrutura oferecida. Ainda foi observado que parte das causas do desperdício estão ligadas aos processos logísticos envolvendo os produtos hortifrutigranjeiros, confirmando a falta de investimento nesta área de atuação e propiciando perdas expressivas de produtos. Desta maneira, Junqueira (1999) revela que a falta de planos de açóes logísticos eficazes aliados às más condiçóes das estradas fazem com que $20 \%$ da safra colhida seja desperdiçada entre a saído do campo até a chegado ao consumidor, já para Rebesco (2004) no Brasil não se possui cultura de investimento na área da logística, por isso, acaba prejudicando e desperdiçando a qualidade dos produtos vinda do campo.

Foi observado que dentro da central de abastecimento, apesar de estar sendo estudado uma possível solução para a destinação das sobras e reaproveitamento do desperdício pela gestão da CEASA Serra, percebeu-se a falta de diálogo da gestão e os comerciantes da central, assim como a falta de um método de destinação mais eficaz, apenas se utilizando do banco de alimentos no qual não se aproveitam todas as potencialidades dos recursos e acabam sendo desperdiçados os alimentos com potencial de redução, reutilização ou reciclagem.

Ainda sobre a CEASA Serra, observou-se a falta de preparação tanto estrutural quanto de treinamento da mão de obra, uma vez que não se disponibilizam dispositivos, 
caixas ou conteiners que possibilitariam a destinação correta dos diferentes tipos de materiais jogados fora. No entanto, também não se percebe a intenção dos comerciantes em separar este material, uma vez que seus funcionários jogam no chão os produtos com avarias sem o menor constrangimento. Para Akutsu et al. (2005) o desperdício está incorporado à nossa cultura, o que acaba por se tornar hábito.

Em relação aos comerciantes, constatou-se além do descaso com a destinação do hortifrutigranjeiros, o descontentamento com a atual gestão da CEASA Serra, o que dificulta as relaçóes e possíveis soluções para o problema. Cunha (2006) avalia a necessidade de articulação social, governamental e dos gestores da instituição, uma vez que programas desenvolvidos nas centrais de abastecimento possuem expressiva relevância em termos de ganhos sociais.

\section{CONSIDERAÇÓES FINAIS}

O presente estudo teve como objetivo geral identificar o destino das sobras dos alimentos hortifrutigranjeiros da CEASA Serra. Na busca de atender a este objetivo, assim como aos específicos, utilizou-se da pesquisa exploratória com abordagem qualitativa e quantitativa, além do estudo ser abordado a partir de um estudo de caso. Para sua realização se utilizou a técnica de entrevista semiestruturada gravada para a gestão pública e para a gestão da CEASA Serra. Por sua vez, o questionário estruturado foi aplicado para os comerciantes da central de abastecimento. Ainda foram utilizados os métodos de análise documental e observação o que complementou a pesquisa.

Primeiramente cabe salientar que o direito a alimentação está previsto pela Constituição Federal, mas apesar do Brasil figurar entre os países que mais produzem alimentos no mundo, ainda há uma parcela da população que sofre com a falta de alimentação adequada. No entanto, grandes quantidades de alimentos são desperdiçadas nas centrais de abastecimento brasileiras diariamente e deixam de chegar a mesa das famílias de baixa renda (CAMPANI, 2003).

Sobre o ponto de vista da gestão pública foi observado que estão sendo trabalhadas açóes que minimizam a quantidade de produtos hortifrutigranjeiros que seriam destinados ao aterro sanitário pelos comerciantes da central, açóes como as feiras ponta de safra e distribuição de hortifrútis em troca de material reciclável, esta efetuada em parceria com a Companhia de Desenvolvimento de Caxias do Sul (CODECA). Mas pôde-se verificar que não há nenhuma ação em estudo que esteja ligada à central de abastecimento, demonstrando a falta de interesse por parte do poder público com relação a investimentos na CEASA Serra.

Por sua vez, ao abordar a questão do desperdício e destino das sobras aos gestores da CEASA Serra, constatou-se a falta de programas que deem suporte e colaborem com a diminuição do problema, além de não haver estrutura adequada para o destinamento correto desses alimentos que são jogados no chão sem nenhum constrangimento, uma vez que está enraizado na cultura dos comerciantes que em sua maioria trabalha da mesma forma há vários anos.

Neste mesmo contexto, verificou-se que os gestores da CEASA Serra, possuem um plano de destinação em fase de planejamento, sendo que este abrangerá a coleta e 
separação dos resíduos da central de abastecimento, assim como a destinação adequada destes produtos. Outra açáo inclusa neste planejamento são projetos de conscientização dos comerciantes que possibilitem a aplicação das demais açóes.

Já no ponto de vista dos comerciantes, percebeu-se um comodismo quanto à situação atual, uma vez que este se declara satisfeito com uma perda média de duas caixas por dia. No entanto, estes comerciantes se dizem dispostos a colaborar em projetos de cunho social, que venham a beneficiar pessoas carentes.

Desta maneira, constrói-se um panorama em que se observa que a gestáo pública não se dispóe a investir em melhorias na CEASA Serra, mesmo com a gestâo da central, buscando alternativas que venham a minimizar os impactos que ocorrem na instituição. Nesse sentido, para os comerciantes, o ideal seria a destinação de seus alimentos às famílias carentes, diferenciando-se da proposta da instituição. Contudo, verifica-se que estes aspectos refletem a falta de interlocução entre estas esferas, dificultando a busca por uma ação única e definitiva para a destinação e redução do desperdício dentro da CEASA Serra.

Recomenda-se que para estudos futuros, aborde-se como são distribuídos os alimentos que são doados ao Banco de Alimentos e como as famílias de baixa renda e instituições assistenciais recebem este recursos, demonstrando como são avaliadas as necessidades dos recebedores e como chegam esses recursos ao seu devido destino. Este estudo teve como limitaçóes a pouca participação das pessoas contatadas que, espontaneamente, resolveram não participar da pesquisa.

\section{REFERÊNCIAS}

ASSOCIAÇÃO BRASILEIRA DAS CENTRAIS DE ABASTECIMENTO -

ABRACEN. 2003. Disponível em <http:/www.abracen.org.br>. Acesso em: 10 out. 2014.

AKUTSU, R. C. et al. A ficha técnica de preparação como instrumento de qualidade na produção de refeições. Revista de Nutriçãao, Campinas, v. 18, n. 2, p. 277-279, 2005.

ACADEMIA DE LETRAS BRASIL - ALB. Academia Mundial de Relaçóes Internacionais \& Academia Mundial de Direito Internacional, 2009. Disponível em: <www.academialetrasbrasil.org.br/galeriamembros/>. Acesso em: 08 mar. 2015.

BORDIN, M. R. Embalagens para frutas. In: SILVA, J. A. A. da; DONADIO, L. C. (Eds.). Pós-colheita de citrus. Jaboticabal: Funep, 2000. p. 33-43. (Boletim Citrícola, 13). Disponível em: <http://www.estacaoexperimental.com.br/documentos/BC_13. pdf\#page=38>. Acesso em: 03 abr. 2015.

BUENO, C. Consumo de alimentos: Alimentar uma população crescente é um dos grandes desafios da atualidade. Reportagem UNIVESP,2013. Disponível em: $<$ http:// univesp.ensinosuperior.sp.gov.br>. Acesso em: 24 ago. 2014.

BUENO, Francisco da Silveira. Minidicionário da Língua Portuguesa. $2^{\circ}$ ed. São Paulo FTD, 2007. 
CAMPANI, D.B. Estudo de viabilidade de tratamento por fermentação láctica de resíduos folhosos da CEASA-RS de Porto Alegre. In: Congresso brasileiro de engenharia sanitária e ambiental, 22 , 2003, Joinvile, Rio de Janeiro: ABES, 2003.

CARABAJAL, Mário. Principais Causas: Fome no Mundo. Tese de mestrado Academia de Letras Brasil 2010. Disponível em: < http://www.academialetrasbrasil.org.br/ TeseFomeMundo18jan10.pdf>. Acesso em: 07 mar. 2015.

CARVALHO; Debora. Desperdício - Custo para todos - Alimentos apodrecem enquanto milhóes de pessoas passam fome. Revista de informação e debate do IPEA. Ano 6. Edição 54 - 30/10/2009. Disponível em <http://ipea.gov.br/>. Acesso em: 05 set. 2014.

CASTELLANELLI, Carlo Alessandro. Estudo da viabilidade de produçáo do biodiesel, obtido através do óleo de fritura usado, na cidade de Santa Maria - RS. Dissertação (Mestrado em Engenharia da Produção) - Programa de Pós-Graduação em Engenharia de Produção, Área de Concentração em Qualidade e Produtividade, da Universidade Federal de Santa Maria (UFSM, RS), Santa Maria - RS, 2008.

CEASA/RS - Ceasa no 4o Seminário Brasileiro de Gestão Ambiental na Agropecuária. Noticia 24/04/2014. Disponível em: <http://www.ceasars.com.br/>. Acesso em: 16 set. 2014.

COMISSÃO ECONÔMICA PARA AMÉRICA LATINA E O CARIBE - CEPAL. Pronunciamento oficial de Jacques Diouf, Diretor Geral da FAO à Cimeira de Roma, 2001. Disponível em: <http://www.cepal.org/>. Acesso em: 10 mar. 2015.

\section{CERQUEIRA-PEREIRA, E. C. Caracterização e comparação de sistemas de} embalagem e transporte de mamáo "solo" destinado ao mercado nacional. 2009. 116 p. Tese (Doutorado em Fitotecnia) - Escola Superior de Agricultura "Luiz de Queiroz", Universidade de São Paulo, Piracicaba, 2009.

CHITARRA, M. I. F; CHITARRA, A. B. Pós-colheita de Frutas e Hortaliças: fisiologia e manuseio. Lavras ESAL/FAEPE, 1990.320p.

COMPANHIA NACIONAL DE ABASTECIMENTO - CONAB. Diagnóstico dos mercados atacadistas de hortigranjeiros. Brasília, DF: CONAB, 2009. Disponível em <http://www.conab.gov.br>. Acesso em: 16 set. 2014.

. A importância de uma central de abastecimento. Brasília, DF: CONAB, 2015. Disponível em: <http://abracen.org.br/wp-content/uploads/2013/11/ApresentacaoDetec. pdf>. Acesso em: 16 set. 2016.

CONFEDERAÇÃO NACIONAL DOS TRANSPORTES - CNT. Pesquisa rodoviária 2005a: relatório gerencial. Brasília, 2005a. Disponível em: <http://www.cnt.org.br>. Acesso em: 13 abr. 2015. 
. Boletim estatístico. Brasília, dez. 2005b. Disponível em: <http://www.cnt.org. br>. Acesso em: 13 abr. 2015.

CUNHA, Altivo Roberto Andrade de Almeida. Dimensóes estratégicas e dilemas das Centrais de Abastecimento no Brasil. Artigo publicado na Revista de Politica Agrícola ano XV-N4- out/nov/dez 2006.

EMPRESA BRASILEIRA DE PESQUISA AGROPECUÁRIA - EMBRAPA. Pesquisas da Embrapa buscam formas de evitar o desperdício de alimentos. Portal do planalto. Publicado em 15de ago.2014. Disponível em <http://brasil.gov.br/>. Acesso em: 05 set. 2014.

FOOD AND AGRICULTURE ORGANIZATION OF THE UNITED NATIONS -

FAO. Cimeira mundial da alimentação. Roma, 10 a 13 de junho de 2001. Disponível em: <http://www.fao.org/>. Acesso em: 10 mar. 2015.

GEIPOT - Empresa Brasileira de Planejamento de Transportes. Disponível em: <http:// www.geipot.gov.br/aempresa/relatoriogestao2001.htm>. Acesso em: 12 out. 2014.

GIL, A.C. Método e Técnicas de Pesquisa Social. 6º edição São Paulo: Atlas, 2012.

GONDIM, Jussara A. Melo, et al. Composiçáo centesimal e de minerais em cascas de frutas. Ciênc. Tecnol. Aliment., v. 25, n. 4, p. 825-827, Out./Dez. 2005.

HAIR JR., J.F.; BADIN, B.; MONEY, A.H.; SAMOUEL, P. Fundamentos de métodos de pesquisa em administraçáo. Tradução Lene Belon Ribeiro. Porto Alegre: Bookman, 2005. 471p.

HORTIFRUTI BRASIL. Quem é o consumidor brasileiro de Frutas e Hortaliças? Revista Hortifruti Brasil, julho de 2011.

INSTITUTO BRASILEIRO DE GEOGRAFIA E ESTATÍSTICA - IBGE. Pesquisa Nacional por Amostra de Domicilio Segurança Alimentar2004/2009. Rio de Janeiro 2010. Disponível em <http: http://www.ibge.gov.br/>. Acesso em: 02 out. 2014.

JUNQUEIRA, A.H. Tendências e desafios da distribuição de produtos hortícolas no Brasil. Revista de Preços Agrícolas, São Paulo, 5-11. 1999.

LANA, M.M.; MOITA, A.W.; NASCIMENTO, E.F.; SOUZA, G.S.; MELO, M.F. Quantificação e caracterização das perdas pós-colheita de cenoura no varejo. Horticultura Brasileira, v. 17, n. 3, p. 295, 1999.

LUENGO, R. F. A. et al. Pós-colheita de hortaliças. Brasília: Embrapa, 2007. v. 1. 100 p. 
MINISTÉRIO DA AGRICULTURA, PECUÁRIA E ABASTECIMENTO - MAPA.

O Papel dos Bancos de Alimentos na Redução dos Desperdícios de Alimentos. 2007.

Disponível em <http://mds.gov.br/>. Acesso em: 18 mar. 2015.

MAUSS, César Volnei; SOUZA, Marco Antônio. Gestáo de custos aplicado no setor público: modelo para mensuração e análise da eficiência e eficácia governamental. São Paulo Atlas, 2008.

MAZZARINO, Jane Márcia; KONRAD, Odorico; TURATTI, Luciana; SILVA, Shirlei Inês Mendes da. Estudo interdisciplinar sobre os processos de gestão dos resíduos sólidos domésticos em Estrela/RS/Brasil. Revista Estudo \& Debate, Lajeado, v. 23, n. 1, p. 28$44,2016$.

MIGUEL, Cauchick, P. A. Metodologia de pesquisa em engenharia da produçáo e gestáo de operaçóes. Rio de Janeiro: Elsevier, 2010. p. 129-144.

MINISTÉRIO DA SAÚDE. Portaria n. 216, de 15 de setembro de 2004. Regulamento Técnico de Boas Práticas para Serviços de Alimentação. Brasília, DF: ANVISA, 2004. Disponível em: www.anvisa.gov.br/e-legis/. Acesso em: 12 mar. 2015.

MINISTÉRIO DO MEIO AMBIENTE - MMA. Documento Agenda 21. Conferência das Naçóes Unidas sobre Meio Ambiente e Desenvolvimento: 1992. Disponível em: http://www.mma.gov.br/. Acessado em: 05 abr. 2015.

MOURA, R. A.; BANZATO, J. M. Embalagem, unitização \& conteinerização. 2. ed. São Paulo: IMAM, 1997. 354 p. (Série Manual de Logística, v. 3).

MÜLLER, Patrícia Carla. Avaliação do desperdício de alimentos na distribuiçáo do almoço servido para os funcionários de um hospital público de Porto Alegre-RS. (Dissertação) Universidade Federal do Rio Grande do Sul Faculdade de Medicina Curso de Graduação em Nutrição, Porto Alegre, 2008.

ORGANIZAÇÃO DAS NAÇŌES UNIDAS - ONU. FAO discute produção mundial de alimentos. FAO notícias 2012. Disponível em: <https://www.fao.org.br/>. Acesso em: 05 set. 2014.

. Uma em cada oito pessoas no mundo passam fome, alerta estudo da ONU. ONU Brasil 2012. Disponível em: <http://www.onu.org.br/>. Acesso em: 14 set. 2014.

PHILERENO, Deivis Cassiano; SARTOR, Natália; ROTTA, Cláudio; KREWER, Evandro José; OLIVEIRA, Sandra Maria de. Qualificação das pessoas com deficiência para o mercado de trabalho: um estudo de caso em Caxias do Sul - RS. Revista Estudo \& Debate, Lajeado, v. 22, n. 1, p. 160-179, 2015.

REBESCO, Elaine. Os vilóes do desperdício. Revista Eco 21, Ano XIV, Edição 96, novembro 2004. Disponível em:<http://eco21.com.br/. Acesso em: 31 ago. 2014. 
RICHARDSON, R. J. Pesquisa Social: Métodos e Técnicas. 3. Ed. São Paulo: Editora Atlas S.A., 1999.

ROESCH, S. M. A. Projetos de estágio e de pesquisa em administraçáo: guia para estágios, trabalhos de conclusão, dissertações e estudo de caso. 3. Ed. São Paulo: Atlas, 2006.

RUFFINO, P. H. P. Proposta de Educaçáo Ambiental como instrumento de apoio a implantação e manutenção de um posto de orientação e recebimento de recicláveis seco em uma escola estadual de ensino fundamental. São Carlos, 2001. Dissertação (Mestrado em Hidráulica e Saneamento) - Escola de Engenharia de São Carlos, Universidade de São Paulo.

SERVIÇO DE ASSUNTOS ESTRATÉGICOS - SAE. Fome aflige 842 milhóes. 2013. Disponível em <http://www.sae.gov.br/>. Acesso em 14 Setembro 2014.

SANDRONI, Paulo. Novíssimo Dicionário de Economia. $7^{\circ}$ ed. São Paulo: Best Seller, 2001.

SANTANA, A. F; OLIVEIRA, L. F. Aproveitamento da casca de melancia na produçáo artesanal de doces alternativos. Alimentos e Nutrição, Araraquara, v. 16, n. 4, p. 363368, 2005.

SILVA, M. B. de; RAMOS, A. M. Composição química, textura e aceitação sensorial de doces em massa elaborados com polpa de banana e banana integral. Revista Ceres, Viçosa, v.56, n.5, p. 551-554, 2009.

SILVA, Mônica M.; BAZOLI, Thiago N. Operaçóes e Logística. São Paulo. Pearson Prentice Hall, 2010.

SILVA, Shirley Machado da. Uma proposta de educação ambiental integrando o princípio dos 3 rs (reduzir, reutilizar e reciclar) nas unidades escolares municipais de Santo Amaro da Imperatriz SC. Dissertação de Mestrado da Universidade Federal de Santa Catarina 2003.

TORRES, Elizabeth Aparecida Ferraz da Silva et al. Composição centesimal e valor calórico de alimentos de origem animal. Cienc. Tecnolol. Aliment., v. 20, n. 2, p. 145150, maio/ago. 2000.

VERGARA, S. C. Métodos de pesquisa em administração. São Paulo: Atlas, 2005

VILELA, J.N; LANA, M.M; NASCIMENTO, E.F; MAKISHIMA, N. O peso das perdas de alimentos para a sociedade: o caso das hortaliças. v. 21.n.2. Brasília, abril/ junho de 2003. 